\title{
On the Strain-Aging of Low-Carbon Steel Sheet*
}

\author{
By Etsurō Shūtō $\bar{o}^{* *}$
}

\begin{abstract}
Synopsis
Low-carbon steel sheets, of which the carbon and nitrogen contents in solution and the grain size were varied by applying different conditions in continuous- or box-annealing, were strain-aged at several temperatures betieen $25^{\circ}$ and $250^{\circ} \mathrm{C}$ after skinpass-rolling. The effects of the interstitial solute elements and the grain size on the change in hardness, futing-sensitivity, yield point elongation and electron microscopic structure during strain-aging were investigated. It was found that the interstitial carbon accelerated the change of hardness, whereas nitrogen accelerated that of the futing point number during strain-aging, especially on aging at $25^{\circ} \mathrm{C}$.

The reasons for the disagreement between the equivalent times calculated by the Hundy's equation for the accelerating strain-aging test and the experimental data were discussed.
\end{abstract}

\section{Introduction}

Recently, in several works in this country, the conventional box-annealing furnaces have been replaced by continuous annealing lines for the annealing of tinplate stocks.

It has been found that the hardness of the tinplate processed through the continuous line is higher and more uniform than that processed on the box-annealing furnace, but the fluting-sensitivity, or the tendency to produce a polygonal can when forming into a round can body, is deteriorated by the process of the continuous annealing.

The high fluting-sensitivity of the continuously annealed low-carbon steel sheet has been believed to be related to the fine grain structure caused by the rapid heating and short soaking in the continuous annealing line and to the enrichment of carbon and/or nitrogen in solution by the rapid cooling, which accelerates strain-aging in the reflowing process of electrolytic tinning. However, the detailed study on the fluting of the continuously annealed low-carbon steel sheets has not been reported.

In the previous paper ${ }^{1)}$ on the effect of annealing condition on the hardness of low-carbon steel the author suggested that the uniformity in the hardness of the continuously annealed low-carbon steel sheet, as compared with that of the box-annealed sheet, could be related to the fact that the larger grain size was accompanied by the enrichment of carbon in solution on cooling at a fairly rapid speed. It is the purpose of the present investigation to continue the previous work. This means investigating the effects of grain size and the content of carbon in solution, which were varied by means of different heat treatments, and those of nitrogen content in solution, on the change of hardness and fluting-sensitivity by strain-aging over a wide temperature range.

\section{Experimental Procedures and Test Specimens}

Cold reduced commercial low-carbon steel strips of $0.24 \mathrm{~mm}$ in thickness and $100 \mathrm{~mm}$ in width, and of the chemical composition listed in Table 1 were received and annealed under the conditions shown in Table 2. The cycle of box-annealing consisted of 16-hr heating, 8-hr soaking and 32-hr cooling to $150^{\circ} \mathrm{C}$. The cycle of continuous annealing which was carried out in a horizontal pilot furnace, was recorded on an electronic recording pyrometer of the recording speed of 3-sec full scale with an almel-chromel thermocouple welded on the strip, and consisted of 60 -sec heating, 48 -sec soaking, 60 -sec slow cooling to $480^{\circ} \mathrm{C}$ and the 48-sec rapid cooling to room temperature. The rapid cooling was performed by jet-spraying a circulating cooled atmosphere gas onto the strip through nozzled plates. The atmosphere gas containing $7 \%$ hydrogen and the balance of nitrogen and of dew point of $-30^{\circ} \mathrm{C}$ was employed for both annealings. Immediately after the annealing or the skinpass-rolling which was conducted with $1.2 \%( \pm 0.1 \%>)$ reduction on a 2 high mill with $250 \mathrm{~mm} \phi$ rolls, specimens were aged in an electric incubator at $25^{\circ}$ and $50^{\circ} \mathrm{C}$, in a boiling water bath at $100^{\circ} \mathrm{C}$ and in an oil bath at $150^{\circ}$ and $250^{\circ} \mathrm{C}$.

Hardness was determined on a Rockwell superficial hardness tester (30T: $30 \mathrm{~kg}$ load, $1 / 16$ in $\phi$ steel ball). A Tensile test was made at a strain rate of $10 \mathrm{~mm} / \mathrm{min}$, with the gauge length of $50 \mathrm{~mm}$. Yield point elongation and strain hardening exponent were determined from the load-strain curve recorded by using a differential transformer type extensometer.

A fluting test was made on a three roll type tester with a bending roll of one inch diameter, and the fluting-sensitivity was evaluated by comparison with a series of standard pieces, where point 1 denoted no

Table 1. Chemical composition of specimens (wt \%)

\begin{tabular}{|c|c|c|c|c|c|c|c|c|c|c|c|c|}
\hline $\begin{array}{l}\text { Specimen } \\
\text { mark }\end{array}$ & $\mathrm{C}$ & $\mathrm{N}$ & Mn & $\mathrm{Si}$ & $\mathrm{P}$ & $\mathrm{S}$ & $\mathrm{Cu}$ & $\mathrm{Ni}$ & $\mathrm{Cr}$ & As & Sn & Sol. Al \\
\hline$A, B, C, D$ & 0.05 & 0.0020 & 0.43 & 0.01 & 0.010 & 0.032 & 0.10 & 0.038 & 0.042 & 0.022 & 0.017 & 0.000 \\
\hline$E$ & 0.10 & 0.0087 & 0.50 & 0.01 & 0.009 & 0.022 & 0.08 & 0.027 & 0.022 & 0.027 & 0.012 & 0.001 \\
\hline
\end{tabular}

* This article is in reference to the lecture delivered before the 66th Grand Lecture Meeting of The Iron \& Steel Institute of Japan in October 1963 in Nagoya. Japanese text was printed in Tetsu-to-Hagané (Journal, Iron \& Steel Institute, Japan), 49 (1963), 10, 14771481.

* Dr. Eng., Composite Research and Development Centre of Toyo Seikan and Toyo Kohan Companies. 
Table 2. Annealing conditions and properties after annealed

\begin{tabular}{c|l|c|c}
\hline $\begin{array}{c}\text { Specimen } \\
\text { mark }\end{array}$ & \multicolumn{1}{|c|}{ Annealing conditions } & $\begin{array}{c}\text { Approximate } \\
\text { carbon content } \\
\text { in solution } \\
\text { (wt. } \%)\end{array}$ & $\begin{array}{c}\text { Grain size } \\
\text { (number/mm² }\end{array}$ \\
\hline$A$ & Box-annealed at $670^{\circ} \mathrm{C}$ & 0 & 7,400 \\
\hline$B$ & $\begin{array}{l}\text { After the same treatment as } \\
\text { specimen } C, \text { heated at } 350^{\circ} \mathrm{C} \\
\times 150 \text { min and slowly cooled }\end{array}$ & 0.00012 & 21,800 \\
\hline$C$ & $\begin{array}{l}\text { Continuously annealed } \\
\text { at } 680^{\circ} \mathrm{C}\end{array}$ & 0.00064 & 22,100 \\
\hline$D$ & $\begin{array}{l}\text { Continuously annealed } \\
\text { at } 900^{\circ} \mathrm{C}\end{array}$ & 0.00164 & 5,800 \\
\hline$E$ & $\begin{array}{l}\text { Continuously annealed } \\
\text { at } 720^{\circ} \mathrm{C}\end{array}$ & 0.00088 & 18,400 \\
\hline
\end{tabular}

fluting and point 8 such severe fluting as could be observed in a fully annealed sheet. The mean value of four measurements was plotted.

Grain size was measured by the counting method (Jeffries' method) specified by A.S.T.M. Electron microscopic observations were made by chromium shadowed acetyl cellulose-carbon replica technique and by transmission technique under $100 \mathrm{KV}$ accelerating voltage, using thin films prepared by electrolytic polishing in an acetic acid and perchloric acid solution.

The approximate carbon content in solution listed in Table 2 was calculated by equation (2) from the electrical resistivity change during 100-min strainaging at $150^{\circ} \mathrm{C}$ observed on the test specimens $10 \%$ strained in tension after annealing. The resistivity was measured by the potentiometric method. A test specimen and a dummy resistance were dipped into an oil bath which was carefully controlled at $0 \pm 0.1^{\circ} \mathrm{C}$ to obtain the $0.01 \%$ accuracy of the resistivity change.

The principal factors that seem to contribute to the change in electrical resistivity within the temperature range concerned in the present experiment are (a) nitrogen (b) lattice defects, (c) carbon in solution, and (d) carbide precipitates.

(a) It is reported that nitrogen in solid solution in equilibrium with $\mathrm{Fe}_{16} \mathrm{~N}_{2}$ in the binary $\mathrm{Fe}-\mathrm{N}$ alloy at $150{ }^{\circ} \mathrm{C}$ is $0.003 \%$, but in low-carbon steels containing Mn more than $0.1 \%$, the precipitation as iron-nitride is considerably retarded, since nitrogen atoms tend to segregate in the solution in the vicinity of $\mathrm{Mn}$ atoms. ${ }^{2}$ In addition, even in specimen $E$ of the highest nitrogen content, precipitates like iron-nitride were not detected by electron transmission as shown later. Hence it may be expected that nitrogen in the specimens of the present work will be mostly in solid solution and barely precipitate during 100-min aging at $150^{\circ} \mathrm{C}$, so that nitrogen will hardly affect the change in electrical resistivity during aging.

(b) As for lattice defects, the electrical resistivity change during 100-min aging at $150^{\circ} \mathrm{C}$ observed on a pure iron sheet fully decarburized and denitrized in wet hydrogen gas was found to be $-0.02 \%$, which may be attributed to the recovery of the lattice defects produced by straining.

(c) As for the relation between the carbon content in solution and electrical resistivity change, Pitsch, et alii $^{3)}$ postulated equation (1) which indicated that the rise by $0.00365 \%$ of carbon in solution is accompanied by the increase by $1 \%$ of electrical resistivity.

$$
\begin{aligned}
& \text { Carbon in solution }(\%)=0.365 \frac{\rho_{\Lambda}-\rho_{\mathrm{Fe}}}{\rho_{\mathrm{Fe}}} \ldots \ldots \ldots \text { (1) } \\
& \begin{aligned}
\rho_{\mathrm{Fe}}: \text { electrical resistivity of pure iron } \\
\rho_{\mathrm{A}}: \text { electrical resistivity of water-quenched iron contain- } \\
\quad \text { ing carbon }
\end{aligned}
\end{aligned}
$$

However, since the equilibrium solubility of carbon in pure iron at $150^{\circ} \mathrm{C}$ is limited to about $1.5 \times 10^{-5} \%$. Equation 1 must be modified for the aging at $150^{\circ} \mathrm{C}$ by taking account of the effect of carbide particles precipitated during aging.

Accordingly, on the basis of the data reported by Pitsch, et alii ${ }^{3)}$ on the electrical resistivity change of binary Fe-C alloys during aging at $149^{\circ} \mathrm{C}$ observed on the specimens water-quenched and strained $4.8 \%$ by tension, equation (2) can be proposed as a modification of equation (1), involving the effect of the recovery of lattice defects and the carbide precipitation.

\section{(Approximate) carbon in solution $(\%)=0.58 \times$ $10^{-2} \times$ Electrical resistivity change during 100 -min aging at $150^{\circ} \mathrm{C}(\%)$}

This equation is the approximate one, since it is based on the data on water-quenched dilute Fe-C alloys containing plenty of super-saturated carbon in solution and, in addition, the electrical resistivity is also dependent upon the shape of the precipitated particles. However, equation (2) gives the relative quantity of carbon in solution contained in each specimen with high accuracy, since the content of carbon evaluated from this equation is in good agreement with that estimated from the carbide precipitation observed by the electron microscopy as shown later. The carbon content evaluated from equation (2) shall be called " approximate carbon content" in solution.

The purpose of the heat treatment adopted for each specimen listed in Table 2 is as follows:

Specimen $A$ was subjected to the conventional boxannealing for tinplate to obtain the representative properties of box-annealed sheets.

Specimen $B$ was prepared by heating the continuously annealed specimen $C$ at a low temperature to reduce carbon in solution, and the effect of carbon in solution on aging was intended for examination in comparison with specimen $C$ of almost the same grain size.

Specimen $C$ was heat-treated at a conventional continuous annealing cycle to obtain a representative continuously annealed sheet.

Specimen $D$ was continuously annealed at the highest soaking temperature to obtain a structure of large grain size containing the highest content of carbon in solution, and is characterized by the structure consisting of the rim zone of a layer of coarse grain with large acicular cementite in the boundaries and the core zone with pearlite, as shown in Photo. 1(a). The rim zone seems to contain more carbon in solution than the core zone, since the precipitation of discrete carbides by aging was more salient in the rim zone, as described 
later. Such irregularity in structure could not be observed in all the other specimens.

Specimen $E$ was prepared in order to examine the effect of nitrogen content, and it contained more carbon in solution than specimen $C$, probably owing to the larger grain size developed by the higher soaking temperature; it also showed severe hardness due to the high nitrogen content.

\section{Results and Discussions}

\section{Hardness}

Hardness changes of specimen $D$ during aging at $25^{\circ}$, $50^{\circ}, 100^{\circ}, 150^{\circ}$ and $250^{\circ} \mathrm{C}$, and of specimens $A, B, C$, and $E$, as annealed and as skinpass-rolled on aging at $250^{\circ} \mathrm{C}$ were represented in Fig. 1. Figs. 1 and 2 (a) indicate that during aging at $250^{\circ} \mathrm{C}$ the hardness of the as-annealed specimen decreases with increasing carbon in solution, namely, in the sequence: $D \rightarrow E$, $C \rightarrow A, B$, and those of specimens $A$ and $D$ as well as $B$ and $C$ of similar grain sizes and of the same steel come very close after $10^{4}$-min aging. It is established that such softening by overaging is associated with the growth of precipitated particles accompanied by the increase of their interparticle spacing. Replica technique was used to examine the structural change during aging.

Photos. 1(b), (c), (d), (e) and (f) represent respectively the electron micrographs of the rim zone in specimen $D$ and the core zones in specimens $D, E, C$ and $A$ strain-aged at $250^{\circ} \mathrm{C}$ for $300-\mathrm{min}$. As can be seen in Photos. 1(b) and (c), the processes of the nucleation and growth of cementite in the rim zone and those in the core zone of specimen $D$ are different. In the rim zone, globular cementites nucleate and grow on the sub-boundaries, while the dendritic cementite ${ }^{4)}$ which looks like an ax nucleates and grows within the matrix. These cementite phases have not any coherence with ferrite phases and easily come off to leave dark and round, or dendritic traces. In the core zone, neither could the nucleation of cementite on the subboundaries and in any other area nor the such traces of cementite be observed by the replica tech- nique as shown in Photo. 1 (c). Consequently, it appears most probable that the rim zone of coarse grains will contain more carbon in solution than the core zone of fine grain. This may be interpreted by the

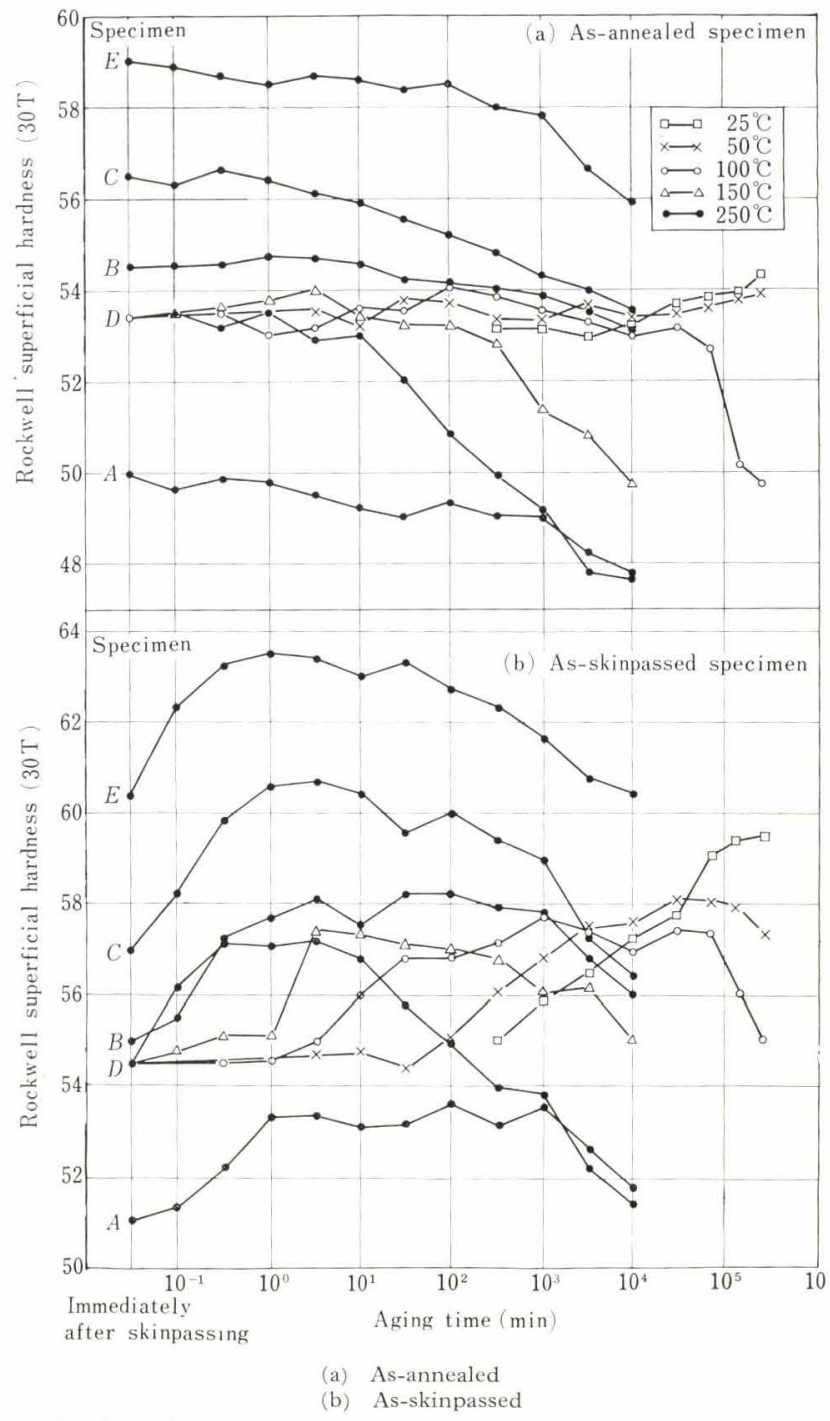

Fig. 1. Change in hardness observed on each specimen during aging at $250^{\circ} \mathrm{C}$ and on specimen $D$ at $25^{\circ}, 50^{\circ}, 100^{\circ}$ and $150^{\circ} \mathrm{C}$

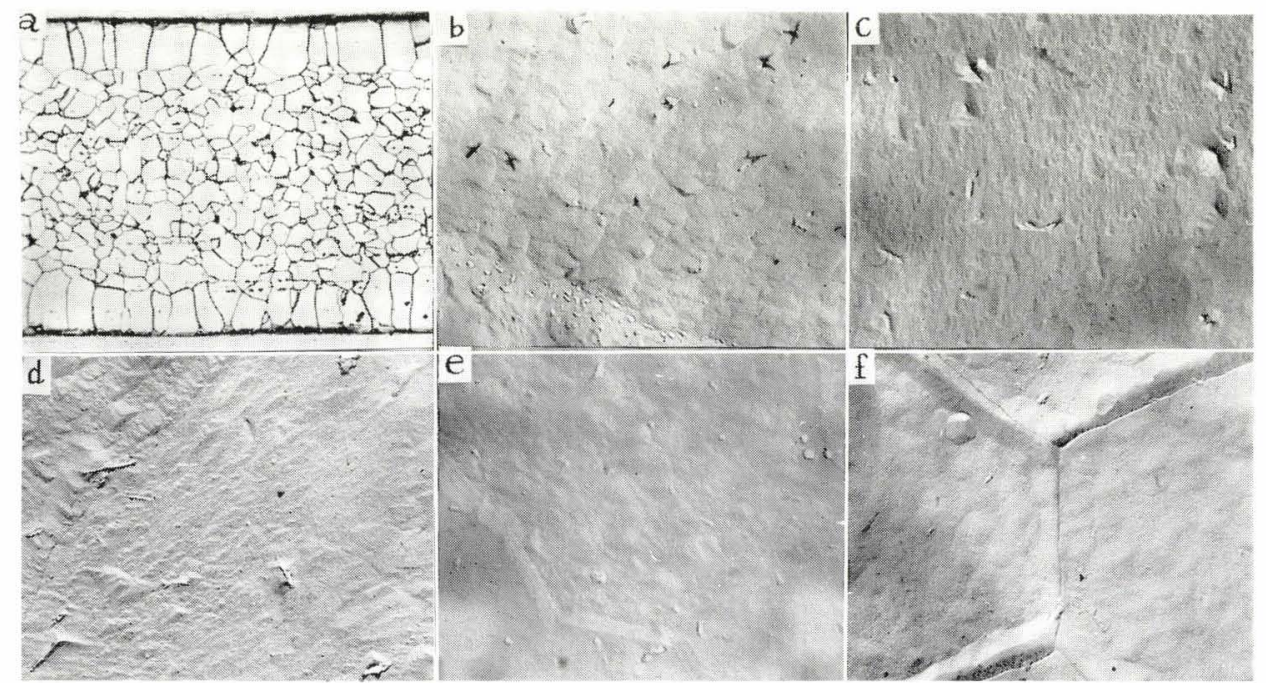

(a) Specimen $D(\times 270)(1 / 2)$

(b) Rim zone of specimen $D(\times 7,500)(1 / 2)$

(c) Core zone of specimen $D(\times 7,5 \mathrm{CO})(1 / 2)$

(d) Rim zone of specimen $E(\times 7,500)(1 / 2)$

(e) Rim zone of specimen $C(\times 7,500)(1 / 2)$

(f) $\operatorname{Rim}$ zone of specimen $A(\times 7,500)(1 / 2)$

Photo. 1. Micrograph showing the heterogeneous structure of specimen $D$ (a) and precipitation after strain-aging for 300 min. at $250^{\circ} \mathrm{C}$ in specimens $D, E, C$ and $A((\mathrm{~b})$ to (f)). Nital and picral etched, 
fact that the clustering or precipitation of carbide during cooling from the soaking temperature will be more sluggish in the rim zone, where the total area of the grain boundaries which act as sinks $\left.{ }^{5)}, 6\right)$ for carbon and the number of pre-existing carbides which act as nuclei are smaller than in the core zone. It seems to be due to the same cause ${ }^{1)}$ that in Table 2, also, carbon in solution decreases in the sequence: specimen $D \rightarrow E \rightarrow$ $C$ with decreasing grain size accompanied by the lowering of the soaking temperature.

As can be seen in Photo. l(d), the precipitated cementites in specimen $E$ are not so discrete as those in the rim zone of specimen $D$, and a few particles of diffused contour are also observed; these particles are more noticeable in the specimens $C$ and $A$ containing less carbon in solution. In specimen $A$ and $B$ no distinct precipitates were observed.

By the replica electron microscopic survey of the rim zone in specimen $D$ aged for various periods at $250^{\circ} \mathrm{C}$, it was found that there were no structural changes within $18 \mathrm{sec}$, while the hardness increased sharply, and globular carbides did not appear on the sub-boundary until after $1 \mathrm{~min}$, when the hardness reached to the maximum value. Dendritic cementites of about $0.2 \mu$ in length initiated precipitation within the matrix after 3 min which grew up to about $0.7 \mu$ after $30 \mathrm{~min}$ and about $1.0 \mu$ length after $10^{4} \mathrm{~min}$. The growth of the dendritic carbide was found to be closely related to the softening by overaging. The hardness of box-annealed specimen $A$ decreased slightly after prolonged aging at $250^{\circ} \mathrm{C}$ as shown in Fig. 1. This softening can also be interpreted as due to the growth of fine carbide particles, although it failed to be confirmed by electron microscopy.

Fig. 1 shows that softening by overaging also takes place during aging at $100^{\circ}$ and $150^{\circ} \mathrm{C}$, although it is not so striking as that observed during aging at $250^{\circ} \mathrm{C}$. Although the hardness of specimen $D$ increases appreciably during the early stage of strainaging, it returns to the initial value after $2.6 \times 10^{5} \mathrm{~min}$ (about 180 days) at $100^{\circ} \mathrm{C}$ and after $10^{4} \mathrm{~min}$ (about 7 days) at $150^{\circ} \mathrm{C}$. Fig. 2 (a) indicates that the decrease of hardness by overaging becomes striking as the carbon content in solution increases.

During aging the as-annealed specimens at $25^{\circ} \mathrm{C}$, only the hardness of specimen $D$ was found to increase slightly after about 180 days, whereas any appreciable change in hardness could not be observed in the other specimens. It was reported $^{7)}$ that the maximum hardness increase observed during quench-aging of water-quenched low-carbon steel was 15 by $R_{30 \mathrm{~T}}$. However, such remarkable hardening did not take place in any specimen of the present work containing far less carbon in solution than those which were water-quenched.

The hardness of specimen $D$ increased noticeably during strain-aging at $25^{\circ} \mathrm{C}$, and after $7 \times 10^{4} \mathrm{~min}$, it reached to a value higher than that obtained by aging at temperatures higher than $50^{\circ} \mathrm{C}$. In Fig. 2(b), approximate carbon content in solution is plotted for each specimen against the hardness increase, or the hardening rate, within the linear hardening period of strain-aging at various temperatures. It is obvious that the hardening rate at $25^{\circ} \mathrm{C}$ increases linearly with the carbon content in solution, whereas such linear relationship can not be held at $50^{\circ} \mathrm{C}$ or over, especially when the carbon content in solution is over $0.0006 \%$.

Photo. 2(a) shows a transmission electron micro-

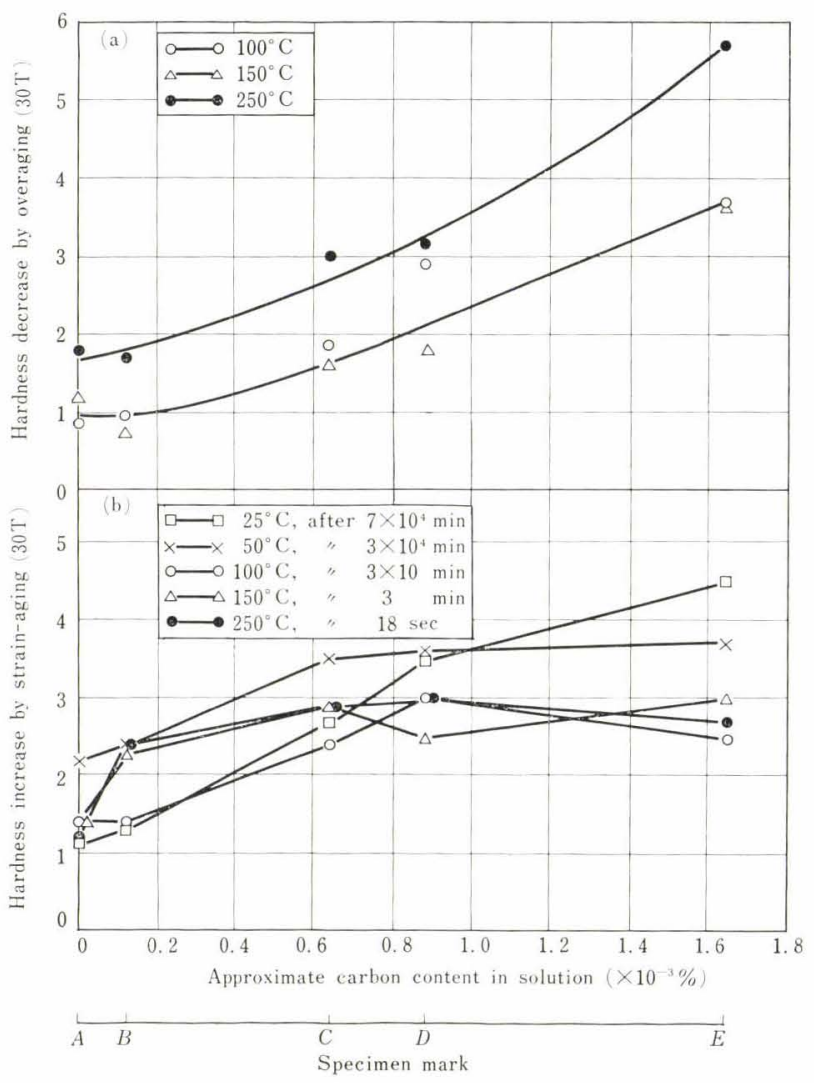

Fig. 2. Relations between approximate carbon content in solution and (a) the hardness decrease by overaging in as-annealed specimens, (b) the hardness increase after the longest strain-aging period at each temperature

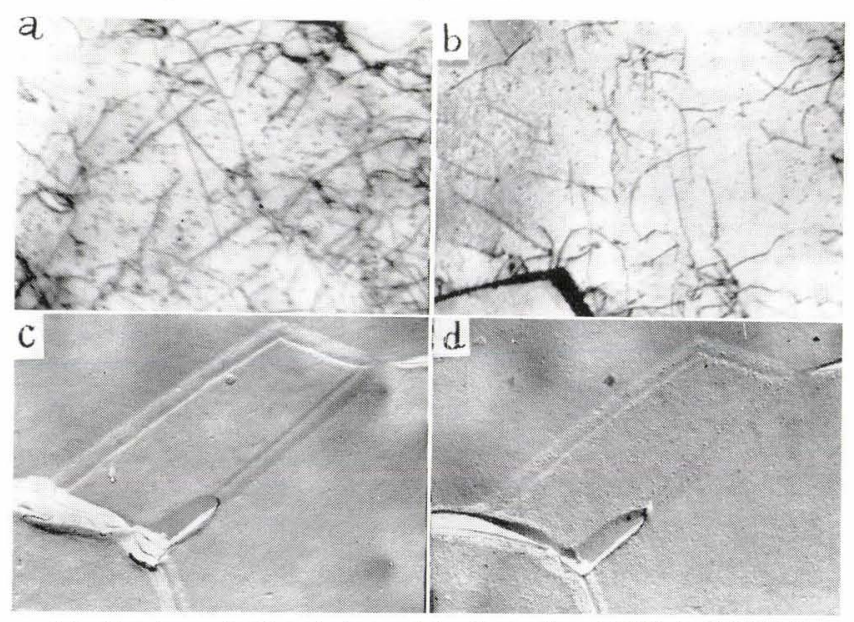

(a) Specimen $D$ after strain-aged for 3 months at $25^{\circ} \mathrm{C}(\times 30,000)(5 /)$

b) Specimen $E$ after strain-aged for 3 months at $25^{\circ} \mathrm{C}(\times 30,000)(5 \%)$

(c) Specimen $D$ immediately after skinpassing $(\times 5,000)(3 / 9)$

(d) The same area as (c), after strain-aged for 3 months at $25^{\circ} \mathrm{C}$ $(\times 5,000)(5 / 9)$

Photo. 2. Transmission electron micrograph of the rim zone in specimens $D$ and $E,((a)$ and $(\mathrm{b}))$ and surface electron micrograph of the rim zone in specimen $D((\mathrm{c})$ and $(\mathrm{d}))$. Nital and picral etched. 
graph of specimen $D$ after 3-month strain-aging at $25^{\circ} \mathrm{C}$, where numerous fine carbide precipitates are observed on dislocations and within the matrix. It seems most probable that these dispersed particles will cause a considerable increase in hardness by acting as obstacles to the plastic flow induced by the indentation of the steel ball of the hardness tester. At higher aging temperatures, the precipitates grow into larger particles and the interparticle spacings become larger, resulting in such hardness falls as shown in Fig. 1. In any other specimens, such numerous particles as in specimen $D$ could not be observed as shown in Photo. 2(b) for specimen $E$. Photo. 2(c) shows the electron microscopic structure of the rim zone of specimen $D$ taken immediately after skinpass-rolling. Photo. 2(d) is that of the same area as Photo. 2(c) after storing for 3 months at $25^{\circ} \mathrm{C}$ in a desiccator with a acetyl cellulose film closely attached on the surface of the specimen, and is characterized by the formation of colonies of fine particles like precipitates in the vicinity of the grain boundaries and acicular cementite phases. Since such particles did not form in all the other specimens, it may be demonstrated that the rim zone of specimen $D$ is most prone to precipitate during aging at $25^{\circ} \mathrm{C}$, although this is a peculiar phenomenon found only on the surface.

It will be interpreted that the slight hardness increase of specimen $A$ during aging at $25^{\circ} \mathrm{C}$, shown in Fig. 2(b), was caused primarily by the pinning of dislocation with nitrogen atmosphere.

It may be concluded from the above discussion that the hardness change during aging of commercial lowcarbon steel is mainly dependent upon the precipitation of carbon and is hardly affected by that of nitrogen or grain size.

\section{Fluting}

From Fig. 3 which represents the change in the fluting-point number of skinpassed specimens during strain-aging, it is evident that the increase of the fluting-point number of specimen $E$ is quite apparent at every temperature. This seems to be associated with the high nitrogen content of this specimen. It may be due to the higher carbon content in solution that the increase of the fluting-point number in specimens $C$ and $D$ is faster than that in specimens $B$ and $A$ of the almost same grain size except at $25^{\circ} \mathrm{C}$; it is likewise due to the larger grain size that specimen $D$ is harder to deteriorate in fluting than specimen $C$.

In general, the fluting-point number is closely related to yield point elongation, and the reason will be discussed in the following.

Fluting is associated with the generation of a number of local bendings of less radius than that of the bending roll, which will become sluggish with the initiation of work hardening in the surface zone of the test specimen, and the radius of the local bending will be reduced with increasing yield point elongation. Moreover, the evaluation of fluting-sensitivity was carried out by comparing the radius of local bendings in the test specimen with that of the standard piece, so that it can be expected that the results of the evaluation are related to the yield point elongation. However, since the surface strain of the present test specimen bent perfectly over the bending roll of the fluting tester is evaluated to be $1 \%$, fluting will not appear in the test specimen with yield point elongation less than $1 \%$. And for test specimens with considerably large yield point elongation, it is also hard to distinguish the values within fluting point 8 . Yet, the results shown in Fig. 3 are consistent with that expected from the characteristics of yield point elongation that increases with decreasing grain size and by strain-aging as the content of carbon and/or nitrogen in solution increase.

The fluting-point number increased remarkably with increasing the nitrogen content at every aging temperature, e.g., as can be seen from the result that the

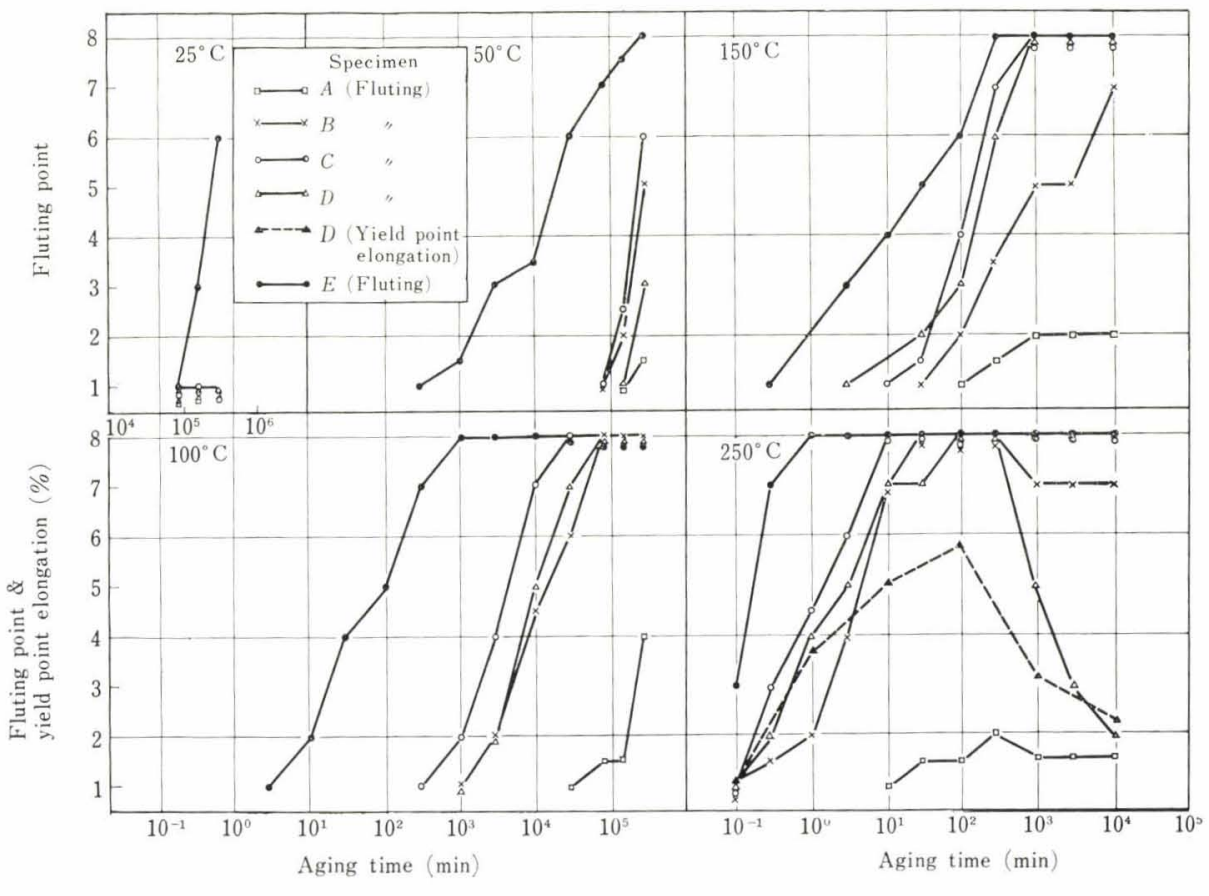

Fig. 3.

Change in fluting and yield point elongation during strain-aging 
fluting did not occur even after 180 -day aging at $25^{\circ} \mathrm{C}$ in all the specimens except specimen $E$, whereas the hardness increase is closely related to the carbon content in solution. Fig. 4 shows the yield point elongation of each specimen 180-day strain-aged at $25^{\circ}, 50^{\circ}$ and $100^{\circ} \mathrm{C}$. At $25^{\circ} \mathrm{C}$, specimen $E$ of the highest nitrogen content shows the largest yield point elongation, and among the other specimens with the lower nitrogen content, the yield point elongations of specimens $C$ and $B$ of the small grain size are higher than those of specimens $D$ and $A$ of the large grain size, showing no influence of carbon in solution. However, on aging at temperatures higher than $50^{\circ} \mathrm{C}$, the yield point elongations of specimens $C$ and $D$ become higher than those of specimens $B$ and $A$, indicating that the effect of carbon in solution becomes appreciable. Most of the curves shown in Fig. 4 are nearly saturated after 180-day aging at $100^{\circ} \mathrm{C}$, and the yield point elongations of specimens $B$ and $A$ of little or no carbon in solution become almost equal to those of the asannealed specimens, but those of specimens $C, D$ and $E$ are higher than those of the as-annealed ones.

The reason why carbon and nitrogen in solution contribute differently to the change in hardness and fluting or yield point elongation during strain-aging, especially at $25^{\circ} \mathrm{C}$, will be discussed below.

The author reported $^{8)}$ previously that yield point elongation $\left(\varepsilon_{y}\right)$ could be related to lower yield stress $\left(\sigma_{y}\right)$, tensile strength $\left(\sigma_{B}\right)$ and strain hardening exponent $(n)$ by equation (3), which implied that yield

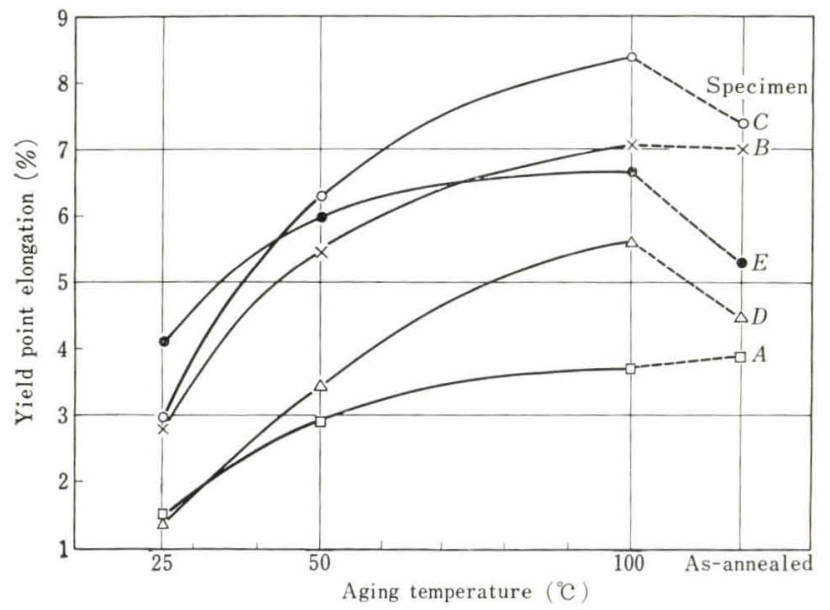

Fig. 4. Relation among grain size, approximate carbon content and the yield point elongation after strain-aging for 180 days at $25^{\circ}, 50^{\circ}$ and $100^{\circ} \mathrm{C}$. (see Tables 1 and 2) point elongation was increased with increasing lower yield stress and strain hardening exponent and with decreasing tensile strength.

$$
\varepsilon_{y}=\frac{n}{2} \cdot\left(\frac{\sigma_{y}}{\sigma_{B}}\right)^{1 / n}+\frac{n}{8} \cdot\left(\frac{\sigma_{y}}{\sigma_{B}}\right)^{2 / n}
$$

Tensile properties before and after 180-day strainaging at $25^{\circ} \mathrm{C}$ and the yield point elongation calculated by equation 3 are listed in Table 3 , in which the increase of the lower yield stress of specimen $E$ is quite pronounced and seems to be associated with the sharp increase of yield point elongation. It is also likely that carbon in solution will contribute to the slight increase in tensile strength, but will have no influence on the increase in lower yield stress during aging at $25^{\circ} \mathrm{C}$.

In specimen $E$ of high nitrogen content in solution, the pinning of dislocation with nitrogen atmosphere will proceed faster during strain-aging according to equation (4). On the contrary, since the solubility of carbon in alpha iron at $25^{\circ} \mathrm{C}$ is far more limited ${ }^{7}$ than nitrogen, it is conceived that during aging at $25^{\circ} \mathrm{C}$ oversaturated carbon will precipitate at the colonies of voids ${ }^{7), 9)}$ within the matrix or on dislocation lines as shown in Photo. 2(a), rather than migrate and segregate uniformly on the whole dislocation line. Recent theor ${ }^{10)}$ on yield stress based on the observations by transmission electron microscopy, suggests that the increase of yield stress by strain-aging is not caused by the extra stress needed to release pinned dislocations from their solute atmosphere as proposed in the early Cottrell's theory, but by the stress needed to force movable dislocations newly generated in the areas of stress concentration such as the interfaces of inclusions or precipitates through those already pinned without release of them. Therefore, it will be easily understood that as the increasing nitrogen in solution accelerates the pinning of dislocations, it will enhance the yield stress. However, the behavior of carbon in solution during aging at $25^{\circ} \mathrm{C}$ may be tentatively explained as follows. The carbon will precipitate as fine carbide particles which may not result in enhanced resistance to the passage of fresh dislocations, since the lattice strain of ferrite induced by the interstitial carbon atom oversaturated in solid solution will be released by the precipitation. Therefore, the total increase of lower yield stress will not be affected much by the carbon in solution within the range of the present experiment. However, at higher aging tem-

Table 3. Tensile properties before and after 180-day strain-aging at $25^{\circ} \mathrm{C}$

\begin{tabular}{|c|c|c|c|c|c|c|c|c|c|c|}
\hline \multirow{2}{*}{$\begin{array}{l}\text { Specimen mark } \\
\text { Strain-aging }\end{array}$} & \multicolumn{2}{|c|}{$A$} & \multicolumn{2}{|c|}{$B$} & \multicolumn{2}{|c|}{ C } & \multicolumn{2}{|c|}{$D$} & \multicolumn{2}{|c|}{$E$} \\
\hline & Before & After & Before & After & Before & After & Before & After & Before & After \\
\hline Strain hardening exponent $(n)$ & 0.198 & 0.188 & 0.194 & 0.197 & 0.187 & 0.190 & 0.177 & 0.180 & 0.193 & 0.191 \\
\hline Lower yield stress $\left(\sigma_{y}\right)\left(\mathrm{kg} / \mathrm{mm}^{2}\right)$ & 20.0 & 25.9 & 26.5 & 30.7 & 27.6 & 34.5 & 23.6 & 30.1 & 28.9 & 39.4 \\
\hline Tensile strength $\left(\sigma_{B}\right)\left(\mathrm{kg} / \mathrm{mm}^{2}\right)$ & 33.1 & 35.7 & 37.0 & 39.1 & 39.1 & 42.5 & 36.8 & 41.3 & 42.5 & 46.1 \\
\hline Yield point elongation $\left(\varepsilon_{y}\right)(\%)$ (calculated)* & - & 1.8 & - & 3.0 & - & 3.2 & - & 1.6 & - & 4.7 \\
\hline
\end{tabular}


peratures, the solubility of carbon in alpha iron increases and the carbon in solution shows a behavior similar to that of nitrogen, so that the increase of lower yield stress during aging and the yield point elongation will increase with carbon in solution.

One of the substantial differences between the factors contributing to the hardness and those to the lower yield stress is that the lower yield stress represents the resistance to the passage of dislocations before the initiation of their tangling during the early stage of plastic flow, while the hardness represents the resistance to the passage of dislocations through tangled dislocations or dislocation cells in the region of advanced plastic flow. Accordingly, it might be tentatively proposed that the strong dependence of the hardness increase on the carbon content in solution at $25^{\circ} \mathrm{C}$ will arise from the enhancement of tangling by the interaction between fine precipitates and dislocations newly generated from their interfaces during the hardness measurement.

Another interesting phenomenon seen in Fig. 3 is that the fluting of specimen $D$ is improved and concurrently the yield point elongation is reduced after strain-aging over $300 \mathrm{~min}$ at $250^{\circ} \mathrm{C}$. It could be shown by the application of equation 3 that such decrease of yield point elongation was associated more with the sharper fall of lower yield stress than with that of tensile strength and the slight change of strain hardening exponent during the overaging stage. This may be due to an unknwon effect of the growth of dendritic cementite on the lower yield stress and tensile strength, but further works are necessary to clarify the mechanism.

\section{On Accelerated Test for Strain-Aging}

It is frequently requested for practical purposes to evaluate in a short time the mechanical properties, especially the yield point elongation, of a skinpassed low-carbon steel sheet after long-time aging at room temperature, and an accelerated test at higher temperatures (usually at $100^{\circ} \mathrm{C}$ ) is carried out.

The equivalent aging times for different temperatures are conventionally determined from equation (5) which was proposed by Hundy ${ }^{11)}$ on the basis of Cottrell and Bilby's equation (4).

$$
n(t)=\alpha n_{0} L\left(\frac{A D t}{k T}\right)^{\frac{2}{3}}
$$

Where,

(n)t: the number of solute atoms per unit volume which segregated to dislocation within the strain-aging time at the temperature $T\left({ }^{\circ} \mathrm{K}\right)$

$n_{0}:$ the number of solute atoms at $t=0$

$D$ : diffusion coefficient of solute

$L:$ total length of edge dislocations per unit volume $\alpha$ and $A:$ constants

$$
\log _{10} \frac{t_{r}}{t}=\beta\left(\frac{1}{T_{r}}-\frac{1}{T}\right)-\log _{10} \frac{T}{T_{r}}
$$

Where,

$t_{r}$ : strain-aging time at the temperature $T_{r}\left({ }^{\circ} \mathrm{K}\right)$

$B: 4,400$ when the diffusion of carbon controls and 4,000 when the diffusion of nitrogen controls
The relations of $t$ and $t_{r}$ obtained from equation (5) are illustrated for $T=25^{\circ} \mathrm{C}$ and $T_{r}=100^{\circ} \mathrm{C}$ by straight lines $\mathrm{I}$ (for carbon) and II (for nitrogen) in Fig. 5, which show that one month at $25^{\circ} \mathrm{C}$ is approximately equivalent to one hour at $100^{\circ} \mathrm{C}$. Recently, however, a few reports ${ }^{12}$, 13) suggesting the disagreement of this equation with experimental data have been published. Hence, the relation between the periods for the identical increase of hardness and of yield point elongation during strain-aging at $25^{\circ}$ and $100^{\circ} \mathrm{C}$ was plotted in Fig. 5 (a) and (b) from the data of the present experiment. The hardness increases of specimens $C$ and $E$ almost conform to equation (5), but that of specimen $D$ containing relatively much carbon in solution is actually faster at $25^{\circ} \mathrm{C}$ than that expected from this, on the contrary, those of specimens equation, $B$ and $A$ with little or no carbon in solution almost conform to this equation during the early stage of aging, but after aging at $25^{\circ} \mathrm{C}$ for 3 months or more, become slower at $25^{\circ} \mathrm{C}$ than that expected from equation (5). The actual time observed from the change in the

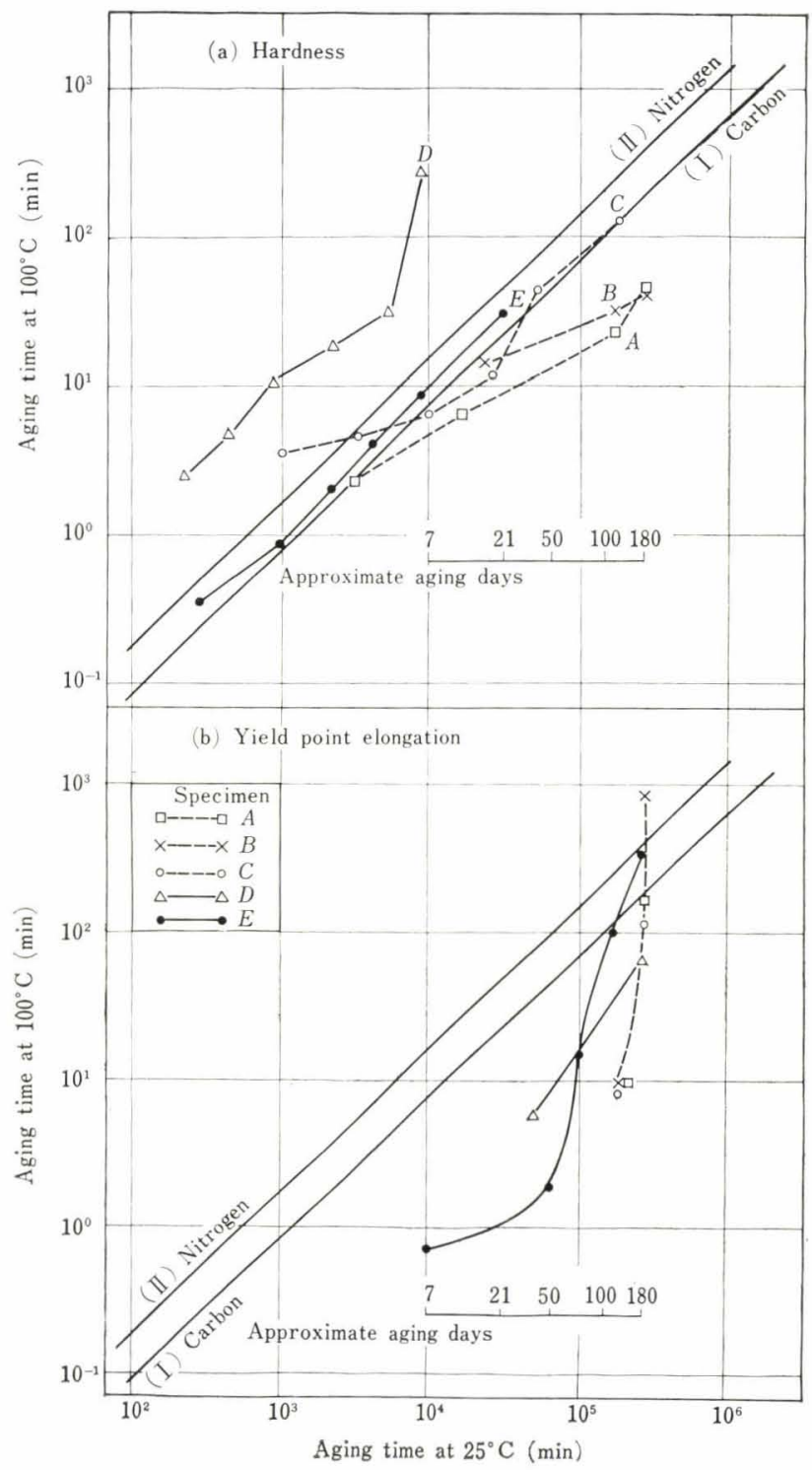

Fig. 5. Relation between the periods for the same increase in (a) hardness and (b) yield point elongation during strain-aging 
yield point elongation of each specimen after 1 to 3 month aging at $25^{\circ} \mathrm{C}$ is ten to twenty times longer than that calculated from equation (5), but after about 3-month aging, it almost accords with the calculated time. The reasons for the disagreement between the observed equivalent times and the values calculated from equation (5) can be considered to be as follows.

Equation (5) was postulated under the following assumptions. ${ }^{11)}$

(a) The change of mechanical properties during strain-aging is proportional to the number of solute atoms segregated on dislocation.

(b) The number of solute atoms in solution per unit volume is identical at each aging temperature $\left(25^{\circ}\right.$ and $100^{\circ} \mathrm{C}$ in this case).

However, as mentioned previously, the following phenomena which seem to be contrary to the above assumptions can be pointed out.

(a) The behavior of segregation and precipitation of carbon on dislocation is dependent upon aging temperature.

(b) The diffusion velocity and solubility of nitrogen in alpha iron are affected by the interaction with $\mathrm{Mn}$ atoms, and the degree of these effects is considered to be dependent upon temperature.

(c) Yield point elongation is a function of lower yield stress, tensile strength and strain hardening exponent, and, therefore, is not always proportional to the segregated amount of solute atom.

Accordingly, it will be expected that equation (5) sometimes disagrees with the experimental data, and should be applied with careful considerations to the conditions of specimens by referring to the figures as shown in Fig. 5 and other experimental data.

\section{Conclusions}

Skinpass-rolled commercial low-carbon steel sheets were strain-aged at several temperatures between $25^{\circ}$ and $250^{\circ} \mathrm{C}$ so as to investigate the effects of carbon and nitrogen in solution, grain size on the change in hardness and fluting-point number during aging.

The results are summarized as follows:

(1) The hardness increase during aging at $25^{\circ} \mathrm{C}$ and its decrease during overaging at $100^{\circ}$ to $250^{\circ} \mathrm{C}$ are highly dependent upon the carbon content in solution, which can be varied by the soaking temperature of continuous annealing, and are independent of the nitrogen content in solution and the grain size. It was clarified by electron microscopy that these phenomena are associated with carbide precipitation.
(2) Fluting point number and yield point elongation are increased with increasing the nitrogen content in solution and with decreasing the grain size during strain-aging at every temperature, and with increasing the carbon content in solution at temperatures higher than $50^{\circ} \mathrm{C}$. However, their increments during aging at $25^{\circ} \mathrm{C}$ are independent of the carbon content in solution, which is assumed to be caused by the preference of fine carbide precipitation within the matrix and at several points on dislocation over the pinning of dislocation with carbon atmosphere. Therefore, the sensitivity of the continuously annealed sheet to fluting or stretcher strain after storing and working at room temperature will be similar to that of the box-annealed sheet of identical grain size and chemical composition.

(3) The equivalent aging times calculated from the Hundy's equation for accelerating strain-aging test were found to deviate from the experimental data, especially the data derived from the observations on the yield point elongation. The Hundy's equation must be applied with careful considerations on the conditions of specimens.

\section{Acknowledgements}

The author wishes to express his cordial gratitude to Prof. Isao Gokyū in University of Tokyo for his valuable advice and Tan Hashida who assisted in transmission electron micrographic study.

\section{REFERENCES}

1) E. Shūtō: Tetsu-to-Hagané, 50 (1964), 5, 766.

2) J. F. Enrietto: Trans. Met. Soc., Amer. Inst. Min., Met. \&ீ Pet. Eng., 224 (1962), 43.

3) W. Pitsch u. K. Lücke: Arch. Eisenhüttenw., 27 (1956), 1, 45.

4) W. C. Leslie, R. M. Fisher \& N. Sen: Acta Met., 7 (1959), 9, 632.

5) P. Stark, B. L. Averbach \& M. Cohen: Acta Met., 6 (1958), 3, 149.

6) J. F. Butler: Trans. Met. Soc., Amer. Inst. Min., Met. \&̊ Pet. Eng., 224 (1962), 89.

7) A. S. Keh \& W. G. Leslie: Material Science Research, 1 (1963), 208. [Plenum Press, New York]

8) E. Shūtō: Sosei-to-Kako (Japan), 4 (1963), 33, 611.

9) W. C. Leslie: Acta Met., 9 (1961), 11, 1004

10) W. C. Leslie \& A. S. Keh: J. Iron Gं Steel Inst. (U.K.), 200 (1962), 722.

$11)$ B. B. Hundy: J. Iron \& Steel Inst. (U.K.), 178 (1954), 34.

12) E. R. Morgan \& J. C. Shyne: Deep Drawing SteelsProceedings of Regional Meeting, Detroit (1957), 51. [Institute of Metals Div. A.I.M.E.]

13) Toyoshima, Shimizu \& Ide: Tetsu-to-Hagané, 46 (1960), 3, 422 . 